\title{
Penerapan Association Rule Menggunakan Apriori Untuk Rekomendasi Produksi Roti
}

\author{
Dwi Hartanti ${ }^{1}$,Indah Nofikasari ${ }^{2}$, Muhammad Arizal Yusuf Hermawan ${ }^{3}$, Dwi Handayani ${ }^{4}$ \\ Universitas Duta Bangsa Surakarta \\ dwihartanti@udb.ac.id $^{1}$, indah nofika@udb.ac.id ${ }^{2}$, muhammad.arizalyusuf@fikom.udb.ac.id ${ }^{3}$, \\ dwi handayani@fikom.udb.ac.id ${ }^{4}$
}

\begin{abstract}
Abstrak - Bisnis mulai berkembang pesat pada masa sekarang. Salah satunya adalah bisnis dalam bidang bakery. Roti Mega Saputera merupakan salah satu usaha dibidang penjulaan roti. Banyak jenis roti yang dijual dengan rasa yang berbeda-beda antara lain roti pisang coklat, roti mocca, roti konde, roti donat, roti pisang coklat goreng, roti kelapa, roti strawberry dan roti nanas. Dalam satu hari banyak transaksi yang terjadi pada pembelian roti. Tujuan dari penelitian yang dilakukan dengan pemodelan association rule untuk mengetahui pola pembelian roti oleh konsumen yang kemudian berdasarkan pola pembelian maka dapat di rekomendasikan produksi roti. Rekomendasi ini akan bermanfaat dalam produksi roti sehingga dalam produksi roti akan lebih optimal dan tidak merugikan pemilik karena banyak roti yang tidak terjual. Pada penelitian yang dilakukan nilai support dan nilai confidence yang digunakan niali support minimal $25 \%$ dan nilai confidence minimal $70 \%$. Hasil penelitian didapatkan hasil untuk kombinasi 2 itemset didapatkan 12 kombinasi 2 itemset, 12 kombinasi 3 itemset dan 4 Kombinasi 4 itemset. Nilai lift ratio paling tinggi 2,073 dan paling rendah 1.285.

Kata Kunci : Association Rule, Algoritma Apriori, Produksi Roti Lift Ratio
\end{abstract}

\begin{abstract}
Business is starting to grow rapidly in the present. One of them is a business in the field of bakery. Mega Saputera Bakery is one of the businesses in the field of bread sales. Many types of bread are sold with different flavors, including brown banana bread, mocca bread, conde bread, donut bread, fried brown banana bread, coconut bread, strawberry bread and pineapple bread. In one day many transactions occur in the purchase of bread. The purpose of this research, which is conducted by modeling the association rule to determine the pattern of purchasing bread by consumers. Based on the purchasing pattern, bread production can be recommended. This recommendation will be useful in the production of bread so that in bread production it will be more optimal and not detrimental to the owner because a lot of bread is not sold. In the research, the support value and confidence value used are at least $25 \%$ and the confidence value is at least $70 \%$. The results showed that for a combination of 2 itemset, there were 12 combinations of 2 itemsets, 12 combinations of 3 itemsets and 4 combinations of 4 itemsets. The highest lift ratio value is 2.073 and the lowest is 1.285.
\end{abstract}

Keywords: Association Rule, Apriori Algorithm, Bread Production, Lift Ratio

\section{PENDAHULUAN}

Perkembangan dalam dunia usaha atau bisnis sangatlah pesat. Baik dari segala bidang usaha yang ada di saat ini. Banyaknya usaha yang bermunculan mengakibatkan tingginya persaingan usaha dalam berbisnis. Pelaku usaha harus melakukan inovasi produksi usaha yang dimiliki. Hal ini dapat dilihat banyaknya produk yang sama ditawarkan pada masyarakat luas. Usaha atau bisnis yang mulai bermmunculan dari bidang makanan, minuman, fashion hingga olahraga.

Salah satu bidang usaha makanan yang menjadi promadona adalah bidang roti. Roti merupakan produk pangan berbahan dasar tepung terigu yang di fermentasi dengan ragi roti atau bahan pengembang lainnya yang diolah dengan cara dipanggang (Mudjajanto dan Yulianti, 2004). Banyak nya jenis yang ada mulai dari roti pisang coklat, roti mocca, roti konde, roti donat, roti pisang coklat goreng, roti kelapa, roti strawberry dan roti nanas yang di produksi membuat dalam melakukan jumlah produksi harus tepat agar roti dapat habis terjual tanpa ada roti yang basi dan berjamur karena tidak laku terjual. Banyaknya roti yang tidak terjual maka akan merugikan pemilik usaha. Transaksi yang terjadi dalam sehari cukup banyak pada usaha roti ini.

Banyaknya jenis dan rasa pada roti memberikan kemudahan dalam pembeli memilih dan membeli roti yang meraka inginkan dan sukai. Melihat data transaksi yang ada dapat dilihat pembeli lebih menyukai rasa tertentu. Maka dengan keadaan yang seperti ini banyak roti yang dengan rasa tertentu tidak laku dan menjadi berjamur dan basi mengakibatkan kerugian. Belum adanya pemanfaatan transaksi penjulaan yang ada untuk mendapatkan pola pembelian roti sehinggan dapat memberikan rekomendasi produksi roti. 
Knowledge Discovery in Databases (KDD) digunakan untuk menjelaskan bagaimana proses dalam menggali informasi yang tersembunyi dalam basis data. Knowledge Discovery in Databases (KDD) dan data mining memiliki kaitan satu sama lain (Bramer and Max, 2007).

Data mining adalah bidang ilmu tentang menganalisis, melakukan proses, pengmpulan, pembersihan data untuk mendapatkan informasi dari data.(Ramadhan \& Wahyudin, 2020). Data Mining juga merupakan proses untuk melakukan penggalian nilai tambah dalam sebuah data yag belum diketahui informasinya yang ada pada data tersebut yang didapatkan dari basis data sistem (Retno, 2017). Data mining memiliki teknik dalam penggalian datanya salah satu tekniknya adalah Association Rule. Association rule adalah suatu prosedur untuk bagaimana kita mencari hubungan antar itemset yang ada pada sebuah data set yang telah di tentukan. (Zahedi \& Chandra, 2012)

Association rule memliki banyak algoritma yang dapat di terapkan salah satunya adalah algoritma Apriori. Apriori adalah algoritma yang digunakan dalam mencapai pola dalam sebuah transaksi yang sering muncul daru beberapa item. Aturan Assosiasi diketahui dari 2 parameter nya yaitu nilai support dan nilai confidence (Riszky \& Sadikin, 2019). Association rule meliputi dua tahap: 1) Mencari kombinasi yang paling sering terjadi dari suatu itemset 2) Mendefinisikan condition dan result.(Moh.Sholik \& Salam, 2018) (Cahyanti, Mujahidin, \& Swedia, 2017). Association Rule yang dilakukan dengan perhitungan nilai support dan nilai confidence (Utami \& Atmojo, 2019). Association rule dikatakan dapat terpenuhi jika nilai support dan nilai confiden lebih besar dari nilai minimum support dan nilai confidence yang telah ditentukan(Han,2006). Sebuah rule asosiasi dikatakan interesting jika nilai support adalah lebih besar dari minimum 2 support dan juga nilai confidence adalah lebih besar dari minimum confidence.(Afdal \& Rosadi, 2019)..

Pada penelitian yang dilakukan oleh Dwi Hartanti dkk association rule dengan menggunakan algoritma apriori dapat diterapkan dalam mengetahui pola pembelian beras sehingga dapat mengetahui dalam penyetokan beras agar tidak berkutu karena kurang laku(Hartanti, Oktaviani and Nofikasari, 2020). Pada penelitian selanjutnya dilakukan oleh Andre Setiawan dkk tentang dengan judul
Implementasi Algoritma Apriori untuk Rekomendasi Kombinasi Produk Penjualan menyimpulkan bahwa apriori dapat digunakan untuk Sistem rekomendasi kombinasi produk yang sering dibeli secara bersamaan yaitu Pom Pom 20x20, Pom Pom 30x30 dan Cake Topper. Memiliki nilai lift ratio yang dihasilkan sebesar 1.18(Setiawan \& Putri, 2020). Pada penelitian yang dilakukan oleh Marina Rajagukguk dkk dengan judul Implementasi Association Rule Mining Untuk Menentukan Pola Kombinasi Makanan dengan Algoritma Apriori menyimpulkan algoritma apriori dapat menemukan pola kombinasi makanan dengan aturan asosiasi dan mengahsilkan 25 aturan asosiasi dengan nilai support $20 \%$ dan nilai confidence 70\%.(Rajagukguk, 2020). Pada penelitian Ratih Wulandari dkk dengan judul Pola Pembelian Produk Berdasarkan Association Rule Data Mining menyimpulkan bahwa penerapan association rule dengan menggunakan FP-Growth dapat membantu dalam penentuan untuk rekomendasi promosi produk berdasarkan pola pembelian konsumen(Wulandari \& Mursidah, 2019).

Berdasarkan permasalahan yang ada penulis akan melakukan penerapan association rule menggunakan algoritma apriori untuk mengetahui pola pembelian konsumen untuk dapat memberikan rekomendasi produksi roti agar dalam melakukan produksi jumlah roti berdasarkan pola pembelian konsumen roti mana yang diminati oleh konsumen.

\section{METODOLOGI PENELITIAN}

Pada penelitian yang dilakukan memiliki tahap penelitian agar penelitian dapat terarah dan fokus. Adapun tahapan penelitian dapat dilihat pada gambar 1 .

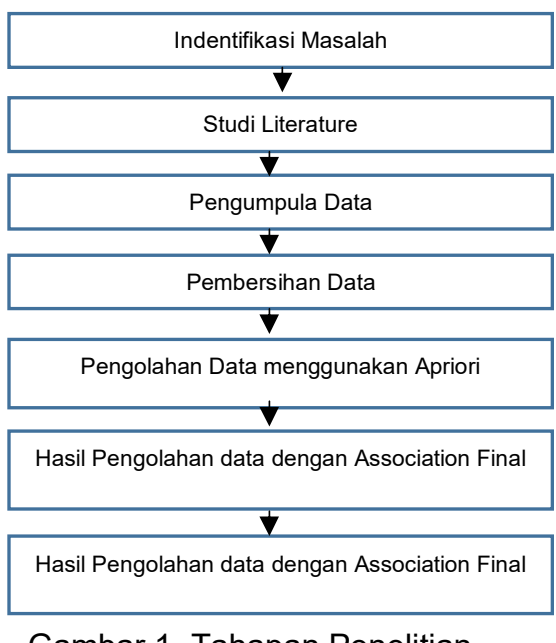

Gambar 1. Tahapan Penelitian 
Keterangan:

1. Melakukan identifikasi yang akan diselesaikan.

2. Melakukan studi literature yang terkait dengan penelitian yang akan dilakukan.

3. Melakukan pengumpulan data yang digunakan dalam penelitian.

4. Melakukan pembersihan data yang tidak digunakan dalam pengolahan data.

5. Melakukan pengolohana data dengan menggunakan algoritma Apriori

6. Mendapatkan hasil dari pengolahan data

7. Melakukan pengolahan dengan Association rule dan didapatkan hasil final association rule

Pengumpulan data dilakukan dengan observasi langsung ke tempat sumber data yaitu Roti Mega Saputera. Data yang didapatkan sebanyak 425 data tansaksi yang kemudian dijadikan sumber data penelitian.

Dalam penelitian ini menggunakan metode pengembangan yaitu Extreme Programing $(\mathrm{XP})$. Adapun tahapan Extreme Programing (XP) sebagai berikut (Sarosa, 2017):

1. Perencanaan

Pada perencanaan mendiskripsikan apa yang harus dikerjakan dalam penelitian yang dilakukan dan menyusun ruang lingkup aplikasi yang dikembangkan.

2. Perancangan

Pada perancangan menggunakan kesederhaan. Dimana pengembangan yang digunakan menggunakan langkah-langkah yang paling mudah untuk mewujudkan fungsionalitas sistem

3. Penulisan Kode Sumber

Konsep pemrograman berpasangan diterapkan dan digunakan secara intensif.

4. Produksi

Keseluruhan modul sistem yang dikembangkan secara komprehensif dalam tahapan ini. Pengujian tersebut bermaksud memastikan bahwa aplikasi yang dikembangkan berjalan dengan optimal.

Penggunaan tahapan Extreme Programing (XP) pada penelitian yang dilakukan menggunakan 2 tahapan yaitu perencanaan dan perancangan.

\section{HASIL DAN PEMBAHASAN}

Pada penelitian association rule menggunakan apriori untuk rekomendasi produksi roti yang dilakukan menggunakan data sebanyak 425 data transaksi yang berada pada Roti Mega Saputera.

\section{Perencanaan}

Data transaksi pembelian roti oleh konsumen terlihat pada Tabel 1 dan Tabel 2.
Tabel 1. Data Transaksi Penjualan

\begin{tabular}{ccccc}
\hline Transaksi & $\begin{array}{c}\text { Pisang } \\
\text { Coklat }\end{array}$ & Mocca & Konde & Donat \\
\hline 1 & 1 & 1 & 0 & 0 \\
2 & 1 & 1 & 1 & 1 \\
3 & 0 & 0 & 1 & 1 \\
4 & 1 & 0 & 0 & 0 \\
5 & 0 & 0 & 1 & 1 \\
6 & 1 & 1 & 0 & 0 \\
7 & 0 & 0 & 0 & 0 \\
8 & 0 & 0 & 1 & 1 \\
9 & 1 & 1 & 0 & 0 \\
10 & 1 & 0 & 1 & 1 \\
11 & 1 & 0 & 0 & 0 \\
12 & 0 & 1 & 1 & 1 \\
13 & 0 & 1 & 1 & 1 \\
14 & 1 & 0 & 1 & 0 \\
15 & 1 & 1 & 0 & 1 \\
16 & 1 & 1 & 0 & 1 \\
17 & 0 & 1 & 0 & 0 \\
18 & 1 & 1 & 1 & 1 \\
19 & 0 & 0 & 0 & 1 \\
20 & 0 & 0 & 1 & 1 \\
$\ldots$ & $\ldots$ & $\ldots$ & $\ldots$ & $\ldots$ \\
425 & 0 & 1 & 0 & 0 \\
\hline
\end{tabular}

Tabel 2. Data Transaksi Penjualan

\begin{tabular}{ccccc}
\hline Transaksi & $\begin{array}{c}\text { Pisang } \\
\text { Coklat } \\
\text { Goreng }\end{array}$ & Kelapa & Strawberry & Nanas \\
\hline 1 & 1 & 1 & 0 & 0 \\
2 & 1 & 0 & 0 & 1 \\
3 & 1 & 0 & 0 & 0 \\
4 & 0 & 1 & 0 & 0 \\
5 & 0 & 0 & 1 & 0 \\
6 & 0 & 1 & 0 & 0 \\
7 & 1 & 0 & 0 & 0 \\
8 & 1 & 1 & 1 & 1 \\
9 & 0 & 0 & 0 & 0 \\
10 & 0 & 0 & 1 & 1 \\
11 & 1 & 0 & 0 & 0 \\
12 & 0 & 0 & 1 & 1 \\
13 & 1 & 1 & 0 & 0 \\
14 & 0 & 0 & 0 & 0 \\
15 & 0 & 0 & 1 & 1 \\
16 & 1 & 1 & 0 & 0 \\
17 & 0 & 0 & 1 & 1 \\
18 & 1 & 0 & 0 & 0 \\
19 & 0 & 0 & 1 & 1 \\
20 & 1 & 1 & 0 & 0 \\
$\ldots$ & $\ldots$ & $\ldots$ & $\ldots$ & $\ldots$ \\
425 & 1 & 0 & 1 & 1 \\
\hline Pada & tabel & 1 & dan tabel & 2 \\
\hline
\end{tabular}
pembelian konsumen pada Roti Mega Saputera. Untuk simbol 1 mendiskripsikan bahwa ada transaksi dan untuk simbol 0 mendiskripsikan tidak ada transaksi.

\section{Perancangan}

\section{a. Penerapan Algoritma Apriori}

Data transaksi penjulaan yang telah didapatkan kemudian dilakukan analisa setiap itemset dari data yang ada. Data akan dilakukan pengolahan untuk mendapatkan kombinasi 
yang sesuai dengan menganalisa data transaksi pembelian roti oleh konsumen.

1. Tahapan penentuan kandidat 1 itemset

Kandidat 1 didapatkan dari itenset yang dijual pada Roti Mega Saputera.

\begin{tabular}{l} 
Tabel 3. Daftar Itemset \\
\hline Itemset \\
\hline Kelapa \\
Strawberry \\
Pisang Coklat \\
Konde \\
Pisang Coklat Goreng \\
Nanas \\
Donat \\
\hline
\end{tabular}

2. Tahapan perhitungan support untuk kombinasi 1 itemset

Nilai support (penunjang) yaitu persentase item atau juga disebut dengan kombinasi item yang ada dalam database (Saefudin \& Fernando, 2020). Tahap ini mencari kombinasi item yang memenuhi syarat minimum dari nilai support dalam database (Novia Lestari, 2017). Dalam perhitungan untuk nilai support (1 Itemset) dengan nilai minimal $25 \%$ dengan perhitungan:

Support $(A)=\frac{\text { jumlah transaksi mengandung } A}{\text { total transaksi }} \ldots \ldots,(1)$

Tabel 4. Nilai Support Kombinasi 1 Itemset

\begin{tabular}{lc}
\hline \multicolumn{1}{c}{ Itemset } & Nilai Support \\
\hline Mocca & 0.584 \\
Kelapa & 0.562 \\
Strawberry & 0.536 \\
Pisang Coklat & 0.496 \\
Konde & 0.480 \\
Pisang Coklat Goreng & 0.466 \\
Nanas & 0.438 \\
Donat & 0.424 \\
\hline
\end{tabular}

Pada tabel 4 terlihat hasil kombinasi 1 dari nilai support minimal $25 \%$. Maka hasil nilai support tersebut selanjutnya masuk ke nilai support 2 kombinasi.

3. Tahapan perhitungan support untuk

kombinasi 2 itemset.

Dalam perhitungan nilai support 2 itemset menggunakana rumus :

Support $(A B)=\frac{\text { jumlah transaksi mengandung } A \text { dan } \mathbb{B}}{\text { total transaksi }}$

Dalam penentuan kandidat 2 itemset yang akan dilakukan didapatkan dari kombinasi 1 itemset yang telah memenuhi syarat yaitu nilai support minimal $25 \%$. Didapatkan 28 kombinasi 2 itemset.
Tabel 5. Kombinasi 2 Itemset

\begin{tabular}{lc}
\hline Kombinasi 2 Itemset & Nilai Support \\
\hline Mocca, Kelapa & 0.440 \\
Mocca, Strawbery & 0.292 \\
Mocca, Pisang Coklat & 0.367 \\
Mocca, Konde & 0.299 \\
Mocca, Pisang Coklat Goreng & 0.214 \\
Mocca, Nanas & 0.273 \\
Mocca, Donat & 0.261 \\
Kelapa, Strawberry & 0.273 \\
Kelapa, Pisang Coklat & 0.341 \\
Kelapa, Konde & 0.282 \\
Kelapa, Pisang Coklat Goreng & 0.207 \\
Kelapa, Nanas & 0.207 \\
Kelapa, Donat & 0.240 \\
Strawberry, Pisang Coklat & 0.247 \\
Strawberry, Konde & 0.169 \\
Strawberry, Pisang & Coklat \\
Goreng & 0.288 \\
Strawberry, Nanas & \\
Strawberry, Donat & 0.266 \\
Pisang Coklat, Konde & 0.202 \\
Pisang Coklat, Pisang Coklat & 0.264 \\
Goreng & 0.099 \\
Pisang Coklat, Nanas & \\
Pisang Coklat, Donat & 0.216 \\
Konde, Pisang Coklat Goreng & 0.184 \\
Konde, Nanas & 0.188 \\
Konde, Donat & 0.245 \\
Pisang Coklat Goreng, Nanas & 0.245 \\
Pisang Coklat Goreng, Donat & 0.195 \\
\hline
\end{tabular}

Dari 27 data kombinasi nilai support 2 kombinasi itemset yang memenuhi syarat minimal $25 \%$ sebanyak 12 kombinasi itemset.

4. Tahapan perhitungan support untuk kombinasi 3 itemset

Dalam penentuan kombinasi 3 itemset didapatkan dari 2 kombinasi yang memenuhi syarat. Pada kombinasi 3 itemset didapatkan sebanyak 27 kombinasi 3 itemset.

Tabel 6. Kombinasi 3 Itemset

\begin{tabular}{llc}
\hline Kombinasi 3 Itemset & & Nilai Support \\
\cline { 1 - 1 } Mocca, Kelapa, Strawberry & & 0.274 \\
Mocca, Kelapa, Pisang Coklat & & 0.301 \\
Mocca, Kelapa, Konde & & 0.288 \\
Goreng & & 0.151 \\
Mocca, Kelapa, Nanas & & \\
Mocca, Kelapa, Donat & & 0.289 \\
Mocca, Starawberry, Pisang & & 0.195 \\
Coklat & & \\
Mocca, Strawberry, Konde & & 0.169 \\
Mocca, Strawberry, Pisang & & 0.296 \\
Coklat Goreng & & \\
Mocca, Strawberry, Nanas & & 0.325 \\
Mocca, Strawberry, Donat & & 0.111 \\
Mocca, Pisang Coklat, Konde & & 0.256 \\
Mocca, Pisang Coklat, Nanas & & 0.329 \\
Mocca, Pisang Coklat, Donat & 0.148 \\
Mocca, Konde, Pisang Coklat & 0.089 \\
Goreng & \\
Mocca, Konde, Nanas & 0.265 \\
\hline
\end{tabular}

ISSN: 2338-9761 (Online), 2338-8145 (Print) 


\begin{tabular}{|c|c|c|}
\hline \multicolumn{2}{|l|}{ Kombinasi 3 Itemset } & Nilai Support \\
\hline \multicolumn{2}{|l|}{ Mocca, Konde, Donat } & 0.162 \\
\hline \multicolumn{2}{|l|}{ Kelapa, Nanas, Donat } & 0.132 \\
\hline $\begin{array}{l}\text { Strawberry, Pisang } \\
\text { Konde }\end{array}$ & Coklat, & 0.292 \\
\hline $\begin{array}{l}\text { Strawberry, Pisang } \\
\text { Nanas }\end{array}$ & Coklat, & 0.106 \\
\hline $\begin{array}{l}\text { Strawberry, Pisang } \\
\text { Goreng, Nanas }\end{array}$ & Coklat & 0.082 \\
\hline $\begin{array}{l}\text { Strawberry, Pisang } \\
\text { Goreng, Donat }\end{array}$ & Coklat & 0.285 \\
\hline Strawberry, Nanas, Dc & & 0.129 \\
\hline Pisang Coklat, Konde, & Janas & 0.132 \\
\hline Pisang Coklat, Konde, & Jonat & 0.129 \\
\hline Pisang Coklat, Nanas, & Donat & 0.115 \\
\hline
\end{tabular}

Dari data kombinasi 3 itemset didapatkan sebanyak 12 kombinasi 3 yang memenuhi syarat minimal nilai support sebesar $25 \%$.

5. Kombinasi 4 itemset

Penentuan kombinasi 4 itemset didapatkan dari 3 kombinasi yang memenuhi syarat. Pada kombinasi 4 itemset didapatkan sebanyak 17 kombinasi 4 itemset.

Tabel 7. Kombinasi 4 Itemset

\begin{tabular}{|c|c|}
\hline Kombinasi 4 Itemset & Nilai Support \\
\hline $\begin{array}{l}\text { Mocca, Kelapa, Strawberry, } \\
\text { Pisang Coklat }\end{array}$ & 0.336 \\
\hline $\begin{array}{l}\text { Mocca, kelapa, Strawberry, } \\
\text { Donat }\end{array}$ & 0.082 \\
\hline $\begin{array}{l}\text { Mocca, Kelapa, Pisang Coklat, } \\
\text { Konde }\end{array}$ & 0.267 \\
\hline $\begin{array}{l}\text { Mocca, Kelapa, Pisang Coklat, } \\
\text { Nanas }\end{array}$ & 0.118 \\
\hline $\begin{array}{l}\text { Mocca, Kelapa, Pisang Coklat, } \\
\text { Donat }\end{array}$ & 0.122 \\
\hline Mocca, Kelapa, Konde, Nanas & 0.104 \\
\hline Mocca, Kelapa, Konde, Donat & 0.315 \\
\hline Mocca, Kelapa, Nanas, Donat & 0.122 \\
\hline $\begin{array}{l}\text { Mocca, Pisang Coklat, Konde, } \\
\text { Nanas }\end{array}$ & 0.104 \\
\hline $\begin{array}{l}\text { Mocca, Pisang Coklat, Konde, } \\
\text { Donat }\end{array}$ & 0.087 \\
\hline $\begin{array}{l}\text { Mocca, Pisang Coklat, Nanas, } \\
\text { Donat }\end{array}$ & 0.096 \\
\hline Mocca, Konde, Nanas, Donat & 0.118 \\
\hline $\begin{array}{l}\text { Kelapa, Pisang Coklat, Konde, } \\
\text { Nanas }\end{array}$ & 0.080 \\
\hline $\begin{array}{l}\text { Kelapa, Pisang Coklat, Konde, } \\
\text { Donat }\end{array}$ & 0.082 \\
\hline $\begin{array}{l}\text { Kelapa, Pisang Coklat, Nanas, } \\
\text { Donat }\end{array}$ & 0.082 \\
\hline Kelapa, Kode, Nanas, Donat & 0.085 \\
\hline
\end{tabular}

Pada kombinasi 4 itemset didapatkan hasil 3 kombinasi 4 yang memenuhi syarat ketentuan yaitu nilai support lebih dari $25 \%$.
6. Tahapan perhitungan confidence itemset Pembentukan Aturan Asosiasi Rule

Semua itemset yang memenuhi support maka akan dicari Itemset yang memenuhi minimum confidence untuk mengetahui kemungkinan aturan asosiasi yang terbentuk(lucyana hutahaean, Safii, \& Efendi Damanik, 2020). Dalam penentuan nilai confidence dari aturan $A \rightarrow B$ diperoleh dari rumus berikut dengan Minimum confidence $70 \%$.

$$
\text { confidence }=P(A \mid B) \frac{\text { Ztransaksi menzandung } A \text { dan日 }}{\text { Vtransaksi mengandug } A} \ldots
$$

Tabel 8. Nilai Confidence

\begin{tabular}{|c|c|c|}
\hline Kombinasi Itemset & $\begin{array}{c}\text { Nilai } \\
\text { Support }\end{array}$ & $\begin{array}{c}\text { Nilai } \\
\text { Confidence }\end{array}$ \\
\hline Mocca, Kelapa & 0.440 & 0.080 \\
\hline Mocca, Strawbery & 0.292 & 0.751 \\
\hline Mocca, Pisang Coklat & 0.367 & 0.653 \\
\hline Mocca, Konde & 0.299 & 0.899 \\
\hline Mocca, Nanas & 0.273 & 0.912 \\
\hline Mocca, Donat & 0.261 & 0.822 \\
\hline Kelapa, Strawberry & 0.273 & 0.825 \\
\hline Kelapa, Pisang Coklat & 0.341 & 0.845 \\
\hline Kelapa, Konde & 0.282 & 0.878 \\
\hline Kelapa, Donat & 0.240 & 0.879 \\
\hline Strawberry, Pisang Coklat & 0.247 & 0.883 \\
\hline $\begin{array}{l}\text { Strawberry, Pisang Coklat } \\
\text { Goreng }\end{array}$ & 0.288 & 0.673 \\
\hline Strawberry, Nanas & 0.266 & 0.883 \\
\hline Pisang Coklat, Konde & 0.264 & 0.781 \\
\hline $\begin{array}{l}\text { Mocca, } \\
\text { Strawberry }\end{array}$ & 0.274 & 0.881 \\
\hline $\begin{array}{l}\text { Mocca, Kelapa, Pisang } \\
\text { Coklat }\end{array}$ & 0.301 & 0.623 \\
\hline Mocca, Kelapa, Konde & 0.288 & 0.434 \\
\hline Mocca, Kelapa, Nanas & 0.289 & 0.673 \\
\hline Mocca, Strawberry, Konde & 0.321 & 0.734 \\
\hline $\begin{array}{l}\text { Mocca, Strawberry, Pisang } \\
\text { Coklat Goreng }\end{array}$ & 0.296 & 0.672 \\
\hline Mocca, Strawberry, Nanas & 0.325 & 0.750 \\
\hline $\begin{array}{l}\text { Mocca, Pisang Coklat, } \\
\text { Konde }\end{array}$ & 0.256 & 0.653 \\
\hline $\begin{array}{l}\text { Mocca, Pisang Coklat, } \\
\text { Nanas }\end{array}$ & 0.329 & 0.567 \\
\hline Mocca, Konde, Nanas & 0.265 & 0.554 \\
\hline $\begin{array}{l}\text { Strawberry, Pisang Coklat, } \\
\text { Konde }\end{array}$ & 0.292 & 0.569 \\
\hline $\begin{array}{l}\text { Strawberry, Pisang Coklat } \\
\text { Goreng, Donat }\end{array}$ & 0.285 & 0.453 \\
\hline $\begin{array}{l}\text { Mocca, Kelapa, } \\
\text { Strawberry, Pisang Coklat }\end{array}$ & 0.336 & 0.332 \\
\hline $\begin{array}{l}\text { Mocca, Kelapa, Pisang } \\
\text { Coklat, Konde }\end{array}$ & 0.267 & 0.367 \\
\hline $\begin{array}{l}\text { Mocca, Kelapa, Konde, } \\
\text { Donat }\end{array}$ & 0.315 & 0.231 \\
\hline
\end{tabular}


7. Hasil Association Rule

Proses association rule disajikan daam bentuk graph yang memudahkan dalam menganalisa data yang sudah diolah dengan mendapatkan nilai support dan nilai confidence.

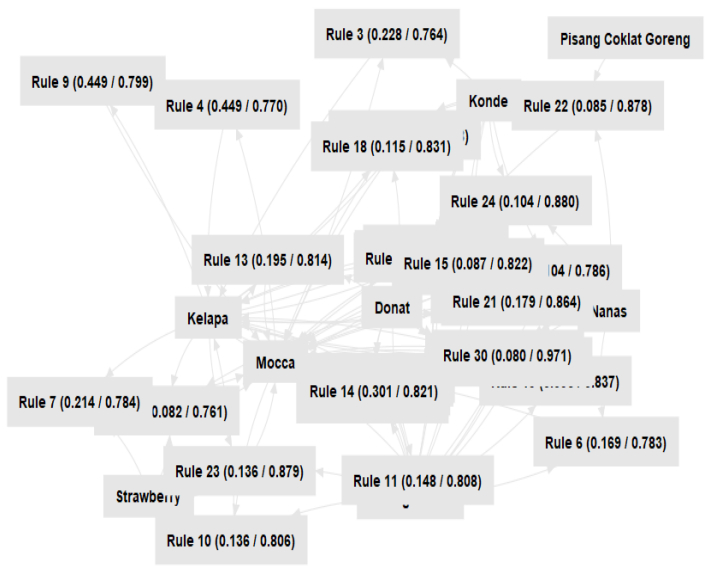

Gambar 2. Graph Hasil Association

Pada gambar 2 merupakan hasil Association dapat melihat nilai untuk setiap rule yaitu nilai support dan nilai confidence.

8. Nilai Lift Ratio

Pada tahapan nilai lift ratio akan menghasilkan nilai untuk mengukur dan menguji kevalidan aturan yang sudah terbentuk. Nilai lift ratio didapatkan dari menghitung kevalidan aturan benarkah produk roti $A$ dibeli dengan bersamaan dengan produk roti $\mathrm{B}$. Kevalidan dikatakan dapat digunakan jika nilai lift ratio lebih dari 1. Hasil analisis lift cenderung mengkonfirmasi ulang bahwa memang ada keterkaitan yang kuat antara barang-barang dalam hasil temuan pola asosiasi (Anwar et al., 2020). Hal ini dapat digunaan sebagai rekomendasi produksi roti agar tidak terlalu banyak produk yang di produksi karena kurang laku (Riszky \& Sadikin, 2019).

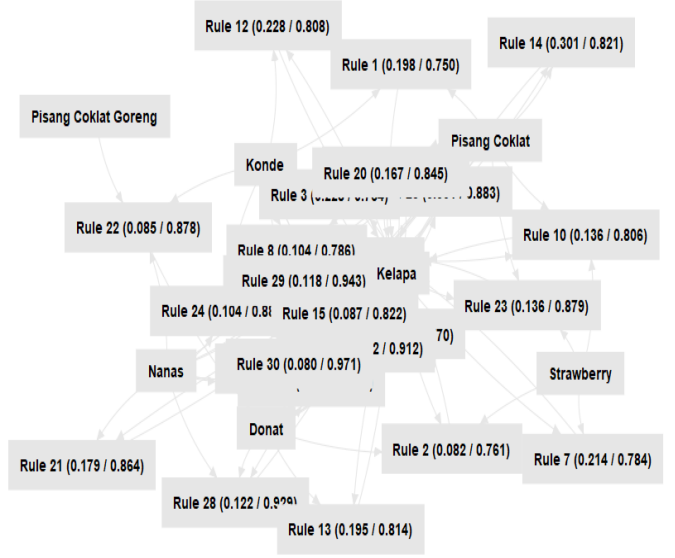

Gambar 3. Nilai Lift Ratio
Dari nilai lift ratio pada gambar 3 dapat dilihat bahwa pada perhitungan lift ratio terdapat nilai lift ratio lebih dari 1 yang berarti valid dalam pembelian produk $A$ dan $B$ jika membeli produk $A$ maka juga akan membeli produk B.

9. Hasil Final Association

Hasil dari Final Association dengan menggunakan algoritma Apriori dapat dilihat pada tabel 9 .

Tabel 9. Hasil Final Association

\begin{tabular}{|c|c|}
\hline No & Hasil Final \\
\hline 1 & $\begin{array}{l}\text { Jika membeli Mocca maka akan membeli } \\
\text { Kelapa }\end{array}$ \\
\hline 2 & $\begin{array}{l}\text { Jika membeli Mocca maka akan membeli } \\
\text { Strawbery }\end{array}$ \\
\hline 3 & $\begin{array}{l}\text { Jika membeli Mocca maka akan membeli } \\
\text { Konde }\end{array}$ \\
\hline 4 & Jika membeli Mocca maka akan Nanas \\
\hline 5 & $\begin{array}{l}\text { Jika membeli Mocca maka akan membeli } \\
\text { Donat }\end{array}$ \\
\hline 6 & $\begin{array}{l}\text { Jika membeli Kelapa maka akan membeli } \\
\text { Strawberry }\end{array}$ \\
\hline 7 & $\begin{array}{l}\text { beli Kelapa maka akan membeli } \\
\text { klat }\end{array}$ \\
\hline 8 & $\begin{array}{l}\text { Jika membeli Kelapa maka akan membeli } \\
\text { Konde }\end{array}$ \\
\hline 9 & Jika membeli Kelapa maka akan Donat \\
\hline 10 & $\begin{array}{l}\text { Jika membeli Strawbery maka akan Pisang } \\
\text { Coklat }\end{array}$ \\
\hline 11 & $\begin{array}{l}\text { Jika membeli Strawberry maka akan } \\
\text { Nanas }\end{array}$ \\
\hline 12 & $\begin{array}{l}\text { Jika membeli Pisang Coklat maka akan } \\
\text { Konde }\end{array}$ \\
\hline 13 & $\begin{array}{l}\text { Jika membeli Mocca maka akan membeli } \\
\text { Kelapa dan Strawberry }\end{array}$ \\
\hline 14 & $\begin{array}{l}\text { Jika membeli Kelapa maka akan membeli } \\
\text { Mocca dan Strawberry }\end{array}$ \\
\hline 15 & $\begin{array}{l}\text { Jika membeli Strawberry maka akan } \\
\text { membeli Mocca dan Kelapa }\end{array}$ \\
\hline 14 & $\begin{array}{l}\text { Jika membeli Mocca maka akan membeli } \\
\text { Strawberry dan Nanas }\end{array}$ \\
\hline 15 & $\begin{array}{l}\text { Jika membeli Strawberry maka akan } \\
\text { membeli Mocca dan Nanas }\end{array}$ \\
\hline 16 & $\begin{array}{l}\text { Jika membeli Nanas maka akan membeli } \\
\text { Strawberry dan Mocca }\end{array}$ \\
\hline
\end{tabular}

Dari tabel 1 maka dapat diketahui untuk roti mocca dan kelapa dapat di produksi lebih banyak karena ketika pembeli membeli roti rasa lain sering kali membeli roti rasa tersebut. Dari hasil pola pembelian roti maka dapat dijaikan sebagai rekomendasi produksi roti dengan tujuan agar jumlah produksi roti tidak berlebihan karena kurang diminati oleh konsumen. 


\section{KESIMPULAN}

Adapun kesimpulan dari penelitian yang telah dilakukan adalah Algoritma apriori dapat diterapkan dalam kasus mengetahui pola pembelian roti yang kemudian dapat di gunakan sebagai rekomendasi produksi roti. Nilai support dan nilai confidence yang digunakan yaitu minimal $25 \%$ untuk nilai support dan $70 \%$ untuk minimal nilai confidence. Nilai lift ratio pada kasus rekomendasi produksi roti lebih dari 1 berarti sangat valid dalam kombinasi produksi. Nilai lift ratio paling tinggi 2,073 dan paling rendah 1.285

\section{REFERENSI}

Afdal, M., \& Rosadi, M. (2019). Penerapan Association Rule Mining Untuk Analisis. 5(1), 99-108.

Anwar, M. T., Purnomo, H. D., Novita, M., Primasari, C. H., Studi, P., Informatika, T., ... Yogyakarta, J. (2020). Implementasi Metode Asosiasi Apriori Untuk. 25(1), 2938.

Bramer, Max (2007). Principles of Data Mining, Springer Science

Cahyanti, M., Mujahidin, M., \& Swedia, E. R. (2017). Penerapan Algoritma Apriori Association Rule Untuk Analisa Nilai Mahasiswa Di Univeristas Gunadarma. 19-23.

Hartanti, Dwi, Oktaviani Intan, Nofikasari, I. (2020). Penerapan Algoritma Apriori Untuk Pola Pembelian Beras Pada UD.Borimin. 7(3), 285-290.

Larose, Daniel T. 2014. Discovering Knowledge in Data: An Introduction to Data Mining (Third Edition). New Jersey : John Wiley \& Sons.

lucyana hutahaean, elfrida, Safii, M., \& Efendi Damanik, B. (2020). Implementasi algoritma apriori pada sistem persediaan barang. JIKO (Jurnal Informatika Dan Komputer), 3(3), 173-180. https://doi.org/10.33387/jiko.v3i3.2192

Moh.Sholik, \& Salam, A. (2018). Implementasi Algoritma Apriori untuk Mencari Asosiasi Barang yang Dijual di E-commerce OrderMas. Techno.COM, 17(2), 158-170.

Mudjajanto, Eddy setyo dan Yulianti, Lilik Noor., 2004. Membuat Aneka Roti. Penebar Swadaya, Jakarta.
Novia Lestari. (2017). Penerapan Data Mining Algoritma Apriori Dalam Sistem Informasi Penjualan. Jurnal Edik Informatika, 3(2), 103-114.

Rajagukguk, M. (2020). Implementasi Association Rule Mining Untuk Menentukan Pola Kombinasi Makanan Dengan Algoritma Apriori. Jurnal Fasilkom, 10(3), 248-254. https://doi.org/10.37859/jf.v10i3.2308

Ramadhan, R., \& Wahyudin, M. I. (2020). Penerapan Metode Asosiasi Menggunakan Algoritma Apriori Terhadap Data Penjualan Jamu Bunda. 5(2), 32-39.

Riszky, A. R., \& Sadikin, M. (2019). Data Mining Menggunakan Algoritma Apriori untuk Rekomendasi Produk bagi Pelanggan. Jurnal Teknologi Dan Sistem Komputer, $7(3)$, 103-108. https://doi.org/10.14710/jtsiskom.7.3.2019. 103-108

Saefudin, S., \& Fernando, D. (2020). Penerapan Data Mining Rekomendasi Buku Menggunakan Algoritma Apriori. JSil (Jurnal Sistem Informasi), 7(1), 50. https://doi.org/10.30656/jsii.v7i1.1899

Setiawan, A., \& Putri, F. P. (2020). Implementasi Algoritma Apriori untuk Rekomendasi Kombinasi Produk Penjualan. Ultimatics: Jurnal Teknik Informatika, 12(1), 66-71. https://doi.org/10.31937/ti.v12i1.1644

Utami, R., \& Atmojo, S. (2019). Implementasi algoritma Apriori untuk Penentuan Weekend Product Promotion pada Minimarket "XYZ." Prosiding Seminar Nasional Sains Dan ..., 315-320. Retrieved from https://ejurnal.itats.ac.id/sntekpan/article/vi ew/552

Wulandari, R., \& Mursidah, I. (2019). Pola Pembelian Produk Berdasarkan Association Rule Data Mining. 3, 1-6.

Zahedi, Z., \& Chandra, C. (2012). Perancangan Program Aplikasi Market Basket Analysis untuk Mendukung Persediaan Barang dengan Metode Fuzzy C-Covering. ComTech: Computer, Mathematics and Engineering Applications, 3(1), 241. https://doi.org/10.21512/comtech.v3i1.241 0 